\title{
Article \\ Estimating Hydraulic Conductivity of Overconsolidated Soils Based on Piezocone Penetration Test (PCPT)
}

\author{
Binyam M. Bekele ${ }^{1, *}$, Chung R. Song ${ }^{1}$, Gyunam Jin ${ }^{2}$ and Mark Lindemann ${ }^{3}$ (D) \\ 1 Department of Civil and Environmental Engineering, University of Nebraska-Lincoln, \\ Lincoln, NE 68588-0007, USA; csong8@unl.edu \\ 2 Land Technology Research Institute, Korea Land Corp., Jinju 52852, Korea; geojin@lh.or.kr \\ 3 Materials and Research Division, Nebraska Department of Transportation, Lincoln, NE 68588-0007, USA; \\ Mark.Lindemann@nebraska.gov \\ * Correspondence: bbekele@huskers.unl.edu
}

Citation: Bekele, B.M.; Song, C.R.; Jin, G.; Lindemann, M. Estimating Hydraulic Conductivity of Overconsolidated Soils Based on Piezocone Penetration Test (PCPT) Infrastructures 2021, 6, 32. https:/ / doi.org/10.3390/infrastructures6030032

Academic Editor: Francesca Dezi

Received: 4 February 2021

Accepted: 23 February 2021

Published: 28 February 2021

Publisher's Note: MDPI stays neutral with regard to jurisdictional claims in published maps and institutional affiliations.

Copyright: (c) 2021 by the authors. Licensee MDPI, Basel, Switzerland. This article is an open access article distributed under the terms and conditions of the Creative Commons Attribution (CC BY) license (https:// creativecommons.org/licenses/by/ $4.0 /)$.
Abstract: Overconsolidated (OC) soils may develop a low or negative pore pressure during PCPT. Thus, it is challenging to develop an "on-the-fly" estimation of hydraulic conductivity from PCPT results. This study presents a method to estimate the hydraulic conductivity of OC soils from PCPT results based on a previously developed method for normally consolidated (NC) soils. To apply the existing method, PCPT pore pressure in OC soils is adjusted by using a correction factor. An equation for the correction factor is derived based on the concepts of critical state soil mechanics, cavity expansion, and consolidation theories. Then, it was reformulated so that traditional cone indices could be used as input parameters. It is shown that the correction factor is mainly influenced by the cone tip resistance, pore pressure, and the rigidity index. The comparison of predicted, which is based on corrected pore pressure and measured hydraulic conductivity showed a good match for four well documented data sets. With the findings of the study, it is expected that an "on-the-fly" estimation of hydraulic conductivity of overconsolidated soils is possible.

Keywords: hydraulic conductivity; overconsolidated soils; PCPT; correction factor

\section{Introduction}

Hydraulic conductivity is an important engineering parameter which is used in the design and analysis of geotechnical tasks such as earth dams, dewatering tasks, slope stability analyses [1]. Hydraulic conductivity may be commonly determined using either laboratory or in situ tests. The piezocone penetration test (PCPT) is one of the in situ tests that is becoming popular due to its versatility, reliability, repeatability, and cost efficiency [2].

Traditionally, PCPT-based estimation of hydraulic conductivity is performed using a dissipation test. In a dissipation test, the penetrating probe is stopped at discrete depths and dissipation of developed excess pore pressure is recorded at $u_{1}$ (cone face) or $u_{2}$ (cone shoulder) locations, as shown in Figure 1 [2]. Then, the dissipation data is interpreted to determine the hydraulic conductivity of soils [3,4]. However, this approach may require a substantial testing time in low hydraulic conductivity soils and does not provide a continuous profile of hydraulic conductivity [2,5].

Recently, "on-the-fly" techniques are becoming attractive [2,5-8]. These techniques are quick and have a potential of providing continuous hydraulic conductivity profiles. Approaches, such as the volume dislocation method [7,9] and coupled theory of mixtures $[2,8,10]$ are frequently employed to predict the hydraulic conductivity of soils "on-the-fly". However, the applicability of "on-the-fly" techniques is somewhat limited to normally consolidated (NC) soils. This may be partly due to the fact that measured excess pore pressure in overconsolidated (OC) soils shows low (but positive) or negative pore pressure depending on the overconsolidation ratio (OCR) [1,11,12]. Therefore, applying the method developed for NC soils, may lead to incorrect results. 


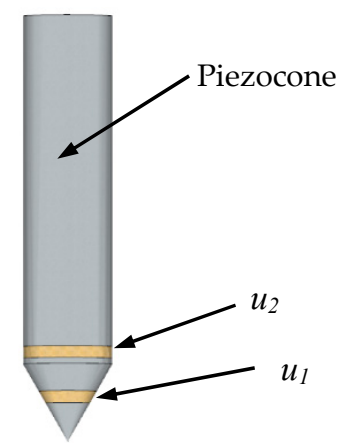

Figure 1. Locations of $u_{1}$ and $u_{2}$ pore pressure measurements.

In this study, a previously developed method by Song and Pulijala [8] was elaborately revised to be applied to $\mathrm{OC}$ soils without resorting to complicated numerical simulations. Before applying this equation, pore pressure in OC soils is corrected. The correction is started by converting OC soils to an equivalent NC soils using the concept of critical state soil mechanics. Then, an equation for the correction factor was derived based on the concepts of critical state soil mechanics, cavity expansion theory, and theory of consolidation. The resulting analytical equation was reformulated using normalized cone indices so that the technique is self-sufficient to compute the hydraulic conductivity of OC soils "on-the-fly".

\section{Previous Work and Proposed Revision for Overconsolidated Soils}

Song and Pulijala [8] applied the coupled theory of mixtures to derive a relationship between the hydraulic conductivity and excess pore pressure response in NC soils. Details of the derivation of equation can be found in Abu-Farsakh et al. [10], and Voyiadjis and Song [2]. The study used the modified cam clay (MCC) model to express the stressstrain relationship while Darcy's law was used to incorporate the pore water flow. After conducting a parametric study with varying MCC model parameters, Song and Pulijala [8] obtained the hydraulic conductivity equation, shown in Equation (1). In this equation, excess pore pressure was taken at the cone face ( $u_{1}$ position). The graphical representation of the equation for a case of $\kappa=0.01$ is shown in Figure 2 .

$$
k=1.75 \times 10^{-6}\left(\frac{[345.25 M+62.32]+[1-0.32 \log (\kappa / 0.1)]}{u_{1, n c}}-1\right)^{1.0564}
$$

where $k$ is the hydraulic conductivity $(\mathrm{m} / \mathrm{s}) ; u_{1, n c}$ is the excess pore pressure at $u_{1}$ position $(\mathrm{kPa}), M$ is the slope of the critical state line (dimensionless), and $\kappa$ is the slope of the unloading-reloading line in $v-\ln p^{\prime}$ axes (dimensionless), where $v$ is the specific volume (dimensionless) and $p^{\prime}$ is the mean effective stress $\left(\mathrm{FL}^{-2}\right)$.

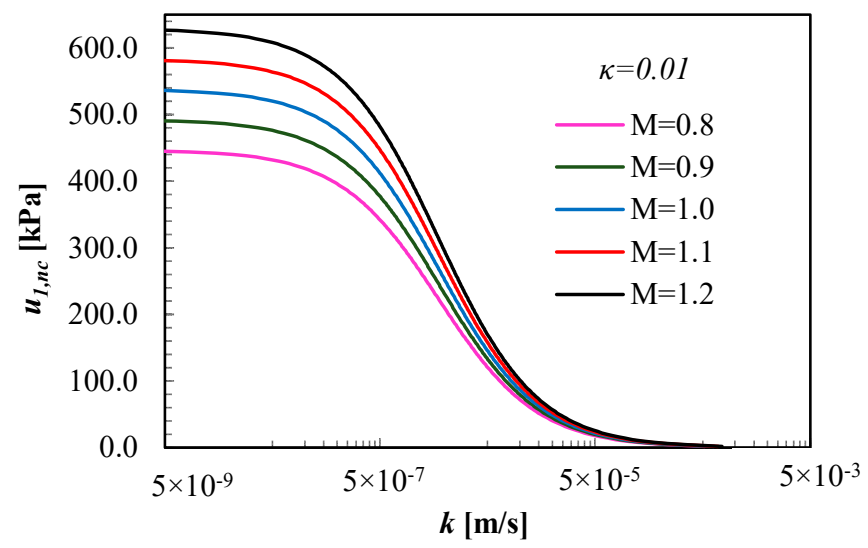

Figure 2. Relationship between hydraulic conductivity and excess pore pressure at $u_{1}$ position in NC soils. 
This study proposed a new method to extend the applicability of Equation (1) to OC soils. The flow chart shown in Figure 3 provide a general description of the proposed approach. First, a measured excess pore pressure at $u_{2}$ location (the cone shoulder) in OC soils is converted to an excess pore pressure that would be measured from equivalent NC soils at $u_{1}$ location using a logically derived correction factor. Then, the corrected excess pore pressure is introduced in Equation (1) to obtain the hydraulic conductivity of OC soils. In subsequent sections, the derivation process of the correction factor is discussed.

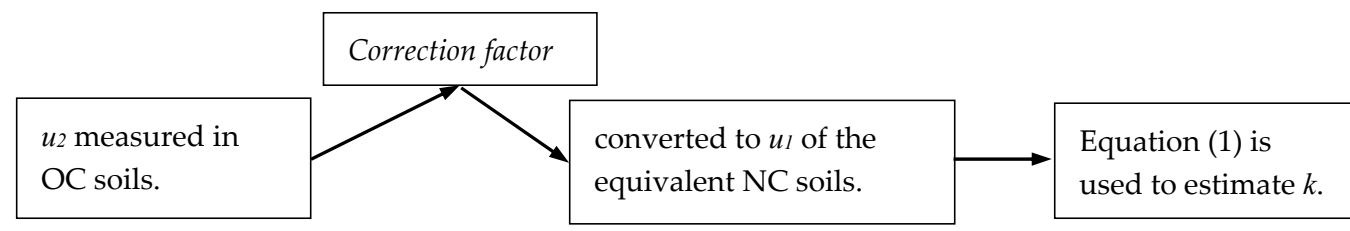

Figure 3. General description of the proposed approach.

\section{Derivation of the Correction Factor}

\subsection{Concept of Equivalent Soils in NC and OC Conditions}

For a saturated porous medium, the hydraulic conductivity is a function of the void ratio, specific surface $\left(S_{S}\right)$, clay content, and kinematic viscosity of the water [13]. The first three variables are soil parameters while, the kinematic viscosity is the property of the water and depends on the subsurface temperature [14]. For the same subsurface temperature condition, the equivalent $\mathrm{NC}$ and $\mathrm{OC}$ soils should preserve the same void ratio, $S_{S}$, and clay content to have the same hydraulic conductivity. The void ratio is affected by the in situ stress state, while the others are mostly dependent on the nature of the soils. A relationship between the void ratio and confining stress is obtained from the concepts of critical state soil mechanics as shown in Figure 4. Accordingly, the magnitudes of confining stresses of the equivalent NC and OC soils which have the same void ratio are shown in the figure. Note that $\sigma_{v, o c}^{\prime}$ in Figure 4 is the in situ effective vertical stress in the OC state $\left(\mathrm{FL}^{-2}\right), \sigma_{v, n c}^{\prime}$ is the in situ effective vertical stress in the equivalent $\mathrm{NC}$ state $\left(\mathrm{FL}^{-2}\right)$, $p^{\prime}{ }_{c}$ is the preconsolidation pressure $\left(\mathrm{FL}^{-2}\right)$, and $v_{0}$ is the initial specific volume given as $v_{0}=1+e_{0}$, where $e_{0}$ is the initial void ratio (dimensionless).

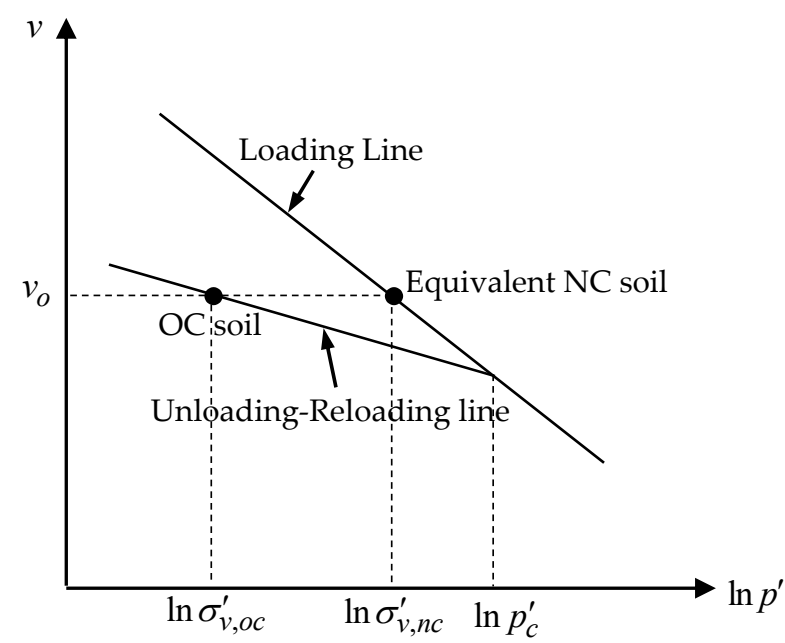

Figure 4. Relationship between equivalent NC and OC soils.

By considering the equations of the loading, and unloading-reloading lines from the critical state soil mechanics concepts [15], a simple relationship between the initial stress states of the NC and OC states is obtained as shown in Equation (2):

$$
\sigma_{v, n c}^{\prime}=\sigma_{v, o c}^{\prime} O C R^{\Lambda},
$$


where OCR is an overconsolidation ratio (dimensionless), and $\Lambda$ is plastic volumetric strain ratio (dimensionless). OCR is the ratio between $p^{\prime}{ }_{c}$ and $\sigma^{\prime}{ }_{v, o c}$, which is given as OCR $=p^{\prime}{ }_{c} / \sigma^{\prime}{ }_{v, O c} . \Lambda$ depends on the slope of the two lines and is given by $\Lambda=1-(\kappa / \lambda)$, where $\lambda$ is the slope of the loading line shown in Figure 4.

\subsection{Definition of the Correction Factor}

The correction factor is a dimensionless number used to convert $u_{2}$ excess pore pressure in OC soils to a $u_{1}$ excess pore pressure in equivalent NC soils. Mathematically, it is expressed as follows:

$$
u_{1, n c}=C\left|u_{2, o c}\right|,
$$

where $C$ is the correction factor (dimensionless), $u_{1, n c}$ is the corrected $u_{1}$ excess pore pressure in the equivalent $\mathrm{NC}$ soils $\left(\mathrm{FL}^{-2}\right)$, and $u_{2, o c}$ is the measured $u_{2}$ excess pore pressure in $\mathrm{OC}$ soils $\left(\mathrm{FL}^{-2}\right)$. An absolute value is taken in Equation (3) due to the fact that $u_{2, o c}$ may become negative values for heavily OC soils. Furthermore, $u_{1, n c}$ may be rewritten as:

$$
u_{1, n c}=\eta u_{1, n c^{\prime}}^{u n d}
$$

where, $\eta$ is a partial drainage parameter that accounts effect of the hydraulic conductivity (dimensionless), and $u_{1, n c}^{u n d}$ is an undrained pore pressure response in the equivalent NC soils $\left(\mathrm{FL}^{-2}\right) . \eta$ varies from 0 to 1 where 0 represents fully drained and 1 represents an undrained condition. Substituting Equation (4) in Equation (3), the correction factor reads:

$$
C=\eta \frac{u_{1, n c}^{u n d}}{\left|u_{2, o c}\right|}=\eta C_{u n d}
$$

where, $C_{\text {und }}$ is an undrained correction factor (dimensionless). The correction factor constitutes composite correction for undrained response and partial drainage.

\subsection{Expression for the Undrained Correction Factor, $C_{\text {und }}$}

The magnitude of $u_{1, n c}^{u n d}$ is estimated using an analytical solution derived based on the cavity expansion theory [16] and the critical state concept (e.g., [15]). An approximate solution provided by Mayne [17] was used in this study as follows:

$$
u_{1, n c}^{u n d}=\frac{4}{3} c_{u} \ln I_{r, n c}
$$

where $c_{u}$ is an undrained shear strength ( $\left.\mathrm{FL}^{-2}\right), I_{r, n c}$ is a rigidity index (dimensionless), which is given by $I_{r, n c}=G / c_{u}$, where $G$ is a shear modulus $\left(\mathrm{FL}^{-2}\right)$. The undrained shear strength, $c_{u}$ is expressed as [17]:

$$
c_{u}=\frac{1}{2} M \sigma_{v, n c}^{\prime}\left(\frac{1}{2}\right)^{\Lambda},
$$

where $M$ is the slope of the critical state line in $p^{\prime}-q$ axes (dimensionless), where $q$ is the deviator stress. In Equation (7), the vertical stress is used instead of the mean stress assuming an isotropic condition. Combining Equations (2) and (5)-(7), an expression for $C_{\text {und }}$ is obtained as shown in Equation (8):

$$
C_{u n d}=C^{*} \frac{\sigma^{\prime}{ }_{v, o c} O C R^{\Lambda}}{\left|u_{2, o c}\right|},
$$

where $C^{*}=(2 / 3) M \ln I_{r, n c}(1 / 2)^{\Lambda}$. Average typical values of $M=1$ and $\Lambda=0.7$ are assumed in the expression of $C^{*}[15,18]$. From Equation $(8)$, it is seen that the undrained correction factor is primarily a function of OCR. The ratio $\sigma^{\prime}{ }_{v, o c} / u_{2, o c}$ has been also used to profile OCR from PCPT results [19]. 


\subsection{Expression for the Partial Drainage Parameter}

The physical meaning of the partial drainage parameter is identical to the degree of consolidation. An expression for this parameter was obtained using the generalized concept of a radial consolidation theory. The solution to the radial consolidation consists of Bessel functions with different orders. Direct use of the infinite summation solution may end up in a complex partial drainage parameter. Therefore, a two-step simplification process was adopted. First, the solution was approximated with an exponential decay function, then, a linearization was performed to further simplify the equation. Exponential decay curves with up to $97 \%$ goodness of fit were obtained, for example, for dissipation curves reported in $[3,20]$. A unified exponential decay function of the form shown in Equation (9) is used in the first step:

$$
\eta=e^{-\alpha T}
$$

where $\alpha$ is a constant (dimensionless), $T$ is a modified time factor (dimensionless) [20]. The modified time factor is obtained by dividing the standard time factor by the square root of the rigidity index in Equation (10):

$$
T=\frac{c t}{r_{c}^{2} \sqrt{I_{r, n c}}}
$$

where $c$ is a radial coefficient of consolidation $\left(\mathrm{L}^{2} \mathrm{~T}^{-1}\right), t$ is a consolidation time $(\mathrm{T})$, and $r_{c}$ is the piezocone radius (L). The coefficient of consolidation may be obtained following [21]:

$$
c=\frac{k M}{\gamma_{w}},
$$

where is an isotropic hydraulic conductivity $\left(\mathrm{LT}^{-1}\right)$, is a constrained modulus $\left(\mathrm{FL}^{-2}\right)$, is the unit weight of water $\left(\mathrm{FL}^{-3}\right)$. The second step involved a linearization of the exponential function by dissecting the slope of the initial tangent line and finding the equation of the line, as shown in Figure 5.

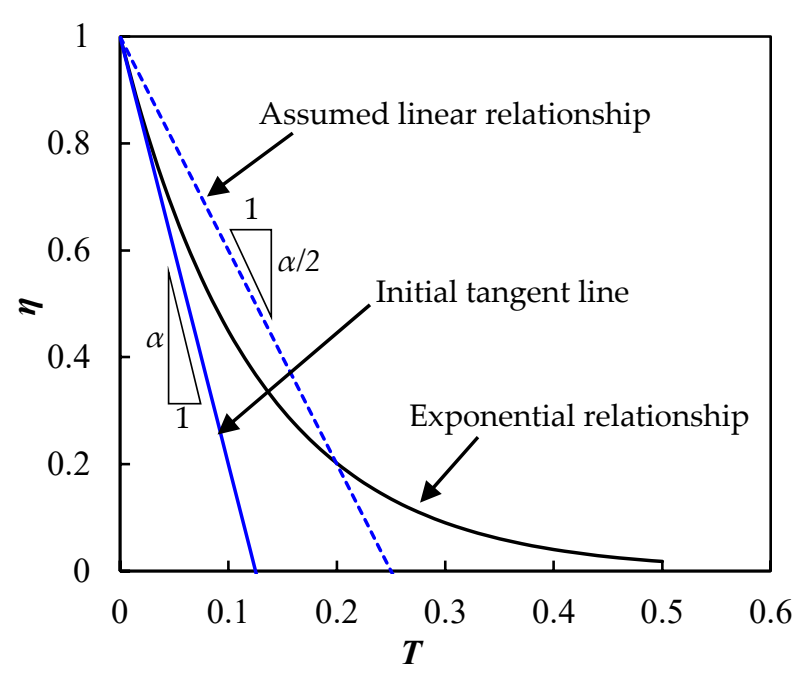

Figure 5. Exponential and assumed linear variation of $\eta$ with $T$.

After finding the tangent line from Equation (9), and substituting Equations (10) and (11), the linearized equation for $\eta$ is obtained as follows:

$$
\eta=1-\left(\frac{\alpha t}{2 \sqrt{I_{r, n c}}} \frac{M}{\gamma_{w} r_{c}^{2}}\right) k,
$$


The partial drainage parameter is a function of the rigidity index, the geometry of the cone, the time of consolidation, and the hydraulic conductivity.

\subsection{Expressing $C_{\text {und }}$ in Terms of Piezocone Parameters}

To maintain real-time estimation of hydraulic conductivity, the undrained correction factor shown in Equation (8) is expressed in terms of normalized PCPT parameters. These parameters could be readily available during the test. Equation (13) shows the normalized cone resistance, normalized friction ratio, and pore pressure ratio, which are among the most widely used normalized cone indices.

$$
Q_{t}=\frac{q_{t}-\sigma_{v}}{\sigma_{v}^{\prime}}, \quad F_{r}=\frac{f_{s}}{q_{t}-\sigma_{v}} \times 100 \%, \quad B_{q}=\frac{u_{2}}{q_{t}-\sigma_{v}},
$$

where $Q_{t}$ is the normalized cone resistance (dimensionless), $F_{r}$ is normalized friction ratio (dimensionless), $B_{q}$ is the pore pressure ratio (dimensionless), $q_{t}$ is corrected cone tip resistance $\left(\mathrm{FL}^{-2}\right)$, is the local sleeve friction $\left(\mathrm{FL}^{-2}\right), u_{2}$ is the excess pore pressure at the cone shoulder $\left(\mathrm{FL}^{-2}\right)$, and $\sigma_{v}$ is the total vertical overburden pressure $\left(\mathrm{FL}^{-2}\right) . O C R$ and $I_{r, n c}$, which are both required in $C_{u n d}$, are written in terms of the normalized cone parameters in the following lines.

Using the normalized parameters, the OCR is expressed in terms of $Q_{t}$, as follows [22]:

$$
O C R=0.33 Q_{t, o c}
$$

where $Q_{t, o c}$ is normalized cone tip resistance measured in OC soils. The rigidity index is first estimated from the cone factor [23]. Then, the cone factor is expressed as a function of the normalized friction ratio [24]. Combing the two steps, the rigidity index was expressed in terms of the normalized friction ratio, as follows:

$$
\ln I_{r, o c}=4.14+1.65 \ln F_{r, o c}
$$

where $I_{r, o c}$ is rigidity index in OC soils, and $F_{r, o c}$ is the normalized friction ratio in OC soils. The estimated rigidity index in OC soils from measured cone indices is converted to a rigidity index of the equivalent NC soils. Making use of the condition that the failure shear stress is the same for both the equivalent NC and OC soils [25] and, taking the shear modulus corresponding to $50 \%$ of the failure shear stress [26], the equivalent NC and the exiting OC soils rigidity indices were related in terms of the OCR, as follows:

$$
\ln \frac{I_{r, n c}}{I_{r, o c}}=\ln \frac{\left(2^{\Lambda}+1\right) O C R^{\Lambda}}{2^{\Lambda}+O C R^{\Lambda}}
$$

In Equation (16), when $O C R=1$, the two rigidity indices will be the same.

Finally, combining Equations (8) and (14)-(16), $C_{\text {und }}$ is rewritten in terms of the normalized cone parameters, as follows:

$$
C_{\text {und }}=0.18 \ln I_{r, n c} \frac{Q_{t, o c}{ }^{-0.3}}{\left|B_{q, o c}\right|} \text {, where : } I_{r, n c}=62.80 F_{r, o c}^{1.65}\left(\frac{1.20 Q_{t, o c}^{0.7}}{1.62+0.46 Q_{t, o c}^{0.7}}\right) \text {, }
$$

where $B_{q, o c}$ is the pore pressure ratio of OC soils. In Equation (17), it can be seen that $C_{\text {und }}$ is fully expressed in terms of parameters that correspond to OC soils.

\subsection{Expressing $\eta$ in Terms of Piezocone Parameters}

To facilitate on-the-fly estimation, the partial drainage factor was expressed in terms of normalized cone indices. Elsworth and Lee [7] did a notable study regarding a link between normalized cone indices and hydraulic conductivity of NC soils. The relationship is given as follows: 


$$
k=\frac{U r_{c} \gamma_{w}}{4 \sigma_{v, n c}^{\prime}}\left(\frac{1}{Q_{t, n c} B_{q, n c}}\right),
$$

where $U$ is the penetration speed $\left(\mathrm{LT}^{-1}\right), Q_{t, n c}$ is the normalized cone tip resistance of the equivalent $\mathrm{NC}$ soils, and $B_{q, n c}$ is the pore pressure ratio of the equivalent NC soils. For a standard PCPT, the penetration speed is $2 \mathrm{~cm} / \mathrm{s}$ and the radius of the cone is $1.90 \mathrm{~cm} . Q_{t, n c}$ and $B_{q, n c}$ are converted to their respective values of $Q_{t, o c}$ and $B_{q, o c}$ to express Equation (18) in terms of OC soil parameters. Consequently, for an equal shear strength condition between OC and equivalent NC soils, it is assumed that $q_{t, n c}-\sigma_{v, n c} \cong q_{t, o c}-\sigma_{v, o c}$. Based on this premise, and combining Equations (2), (3) and (13), the relationship shown in Equation (19) is obtained:

$$
Q_{t, n c}=Q_{t, o c} O C R^{-\Lambda}, \quad B_{q, n c}=\frac{C}{1.3}\left|B_{q, o c}\right|,
$$

The number 1.3 appeared in Equation (19) due to the need to convert $u_{2, n c}$ to $u_{1, n c}$ [23]. The constrained modulus, $M$ is correlated with the net cone tip resistance following Mayne [27], as follows:

$$
M=5\left(q_{t, o c}-\sigma_{v, o c}\right)
$$

Finally, by combining Equations (12) and (18)-(20), the partial drainage parameter is rewritten in terms of a normalized cone parameter, as follows:

$$
\eta=1-0.85\left(\frac{\alpha t}{C\left|B_{q, o c}\right| \sqrt{I_{r, n c}}}\right)
$$

It can be observed that Equation (21) is expressed in terms of parameters that pertain to OC soils.

\subsection{The Correction Factor and Estimation of $\alpha t$}

The correction factor is obtained by substituting the expressions in Equations (17) and (21) in Equation (5). The resulting quadratic equation is solved, and the following expression is obtained:

$$
C=\frac{1}{2} C_{u n d} \pm \frac{1}{2} \sqrt{C_{u n d}{ }^{2}-\frac{3.4 \alpha t C_{u n d}}{\left|B_{q, o c}\right| \sqrt{I_{r, n c}}}}
$$

In the determination of $\alpha t$, the consolidation time must be small enough to mimic instantaneous pore pressure response during PCPT. However, a discrete time must be used in Equation (22) to complete the equation. In fact, consolidation time must be assumed as very small in soils with a low rigidity index (those showing a rapid consolidation) while a relatively higher value may be assumed in rigid soils (those showing a slow consolidation). This explanation is only qualitative. Rather, a quantitative approach is favored to obtain the correction factor. Therefore, an appropriate value of $\alpha t$ is estimated based on the requirement that the quantity within the square root sign must not be negative and based on the fact that the consolidation time is governed by soils with a least rigidity index. A typical least rigidity index of 20 is assumed [9]. Applying these assumptions, $\alpha t$ is written as:

$$
\alpha t=\frac{\left|B_{q, o c}\right| \sqrt{20}}{3.4} C_{\text {und }}
$$

In Equation (23), it can be noted that the time scale is not constant and varies with measured $B_{q, o c}$. Substituting Equation (23) in Equation (22), the complete correction factor reads:

$$
C=\eta C_{\text {und }}=\frac{1}{2}\left(1 \pm \sqrt{1-\frac{4.50}{\sqrt{I_{r, n c}}}}\right) C_{\text {und }}
$$


From Equation (24), the correction factor is dependent on cone tip resistance, pore pressure, and rigidity index. Particularly, the partial drainage parameter is a function of rigidity index. Moreover, Equation (24) showed that, for the same input parameters, two correction factors are possible. One correction factor is more than half of the undrained correction and the other is less than half of the undrained correction. In heavily OC fine grained soils, the measured pore pressure could be lower because of the dilatory responses while, on the contrary, in sand soils, the measured pore pressure is low because of free drainage. Therefore, higher correction factors are naturally expected in soils with dilatory response and lower correction factors are expected in the free draining soils. Correction of more than half of the undrained correction is assigned to the dilative soils and less than half to the free draining soils. The normalized Soil Behavior Type (SBTn) chart is utilized to differentiate sands from dilative fine-grained soils [28]. Thus, clean sands and silty sands with SBTn index, $I_{c}$, ranging from 1.31 to 2.05 and $F_{r, o c}<1$ are assigned a lower correction.

\section{Estimation of Hydraulic Conductivity in OC Soils}

Measured pore pressure is corrected using Equation (24) and substituted in Equation (1) to estimate the hydraulic conductivity of OC soils.

$$
k=1.75 \times 10^{-6}\left(\frac{[345.25 M+62.32]+[1-0.32 \log (\kappa / 0.1)]}{C\left|u_{2, o c}\right|}-1\right)^{1.0564}
$$

Equation (25) may experience a singular condition when the hydraulic conductivity is extremely low (corrected pore pressure is high). For such scenarios, a cut-off hydraulic conductivity was set to $5 \times 10^{-9} \mathrm{~m} / \mathrm{s}$ [8]. Equation (25) involves several PCPT parameters and measured pore pressure data (every $0.02 \mathrm{~m}$ depth). Therefore, to facilitate the computation process, an excel template is prepared-the steps are shown in Figure 6.

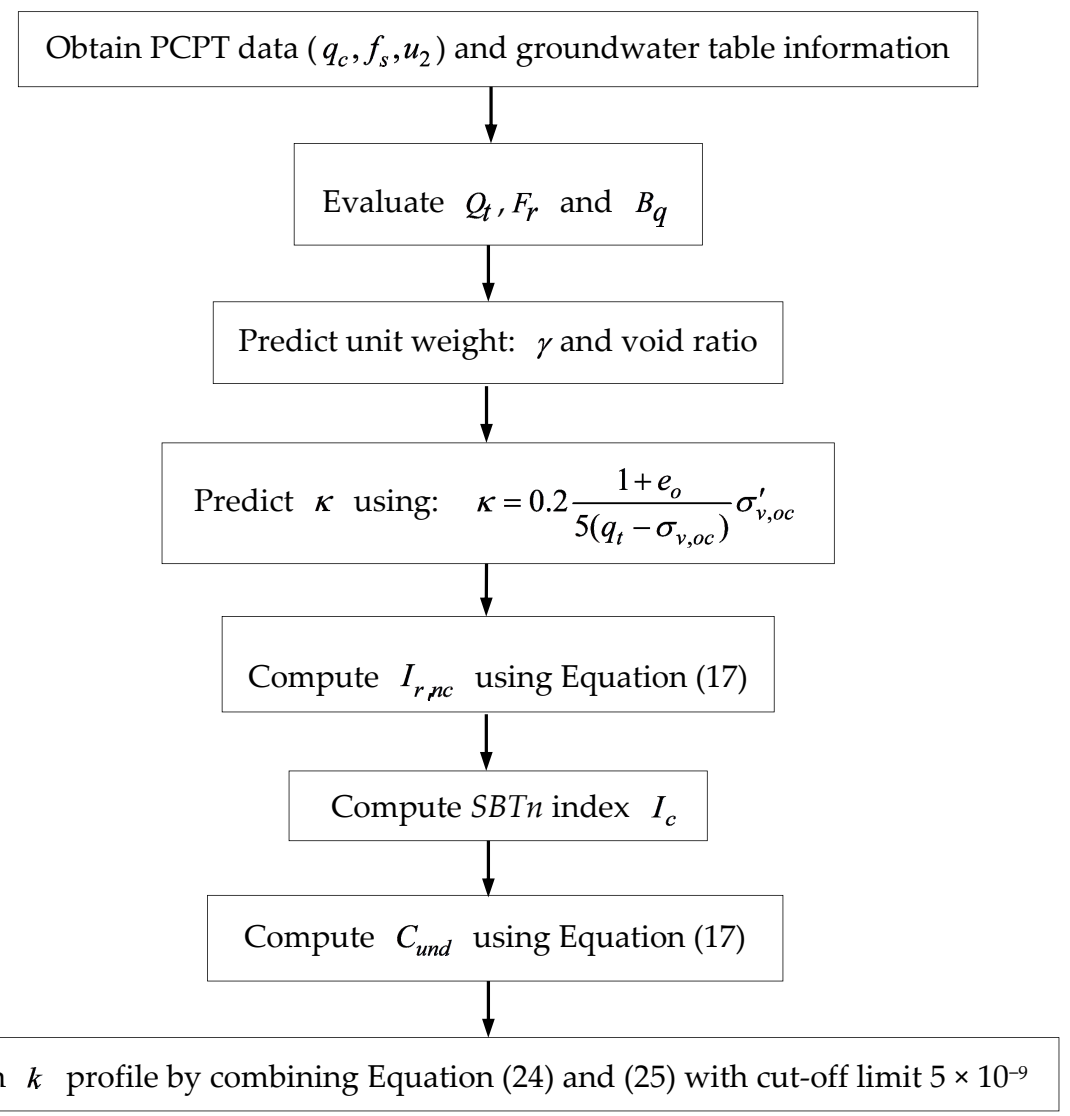

Figure 6. Steps used to compute hydraulic conductivity of OC soils from PCPT (predictions for unit weight and $\kappa$ are obtained from Robertson and Cabal [29] and Song and Pulijala [8]). 


\section{Verification with Test Data from Different Sites}

\subsection{Lincoln, NE, USA}

This site is located in the northwest of Lincoln, NE, USA [5]. It consists of glacial till formation containing overconsolidated clays. The classification of soils showed that it is predominately composed of clays with medium to high plasticity (with unified soil classification of $\mathrm{CL}$ and $\mathrm{CH}$ ). From a depth of 3 to $8 \mathrm{~m}$, the clay-like layers contain traces of fine sands which give rise to relatively higher hydraulic conductivities. The groundwater table was observed at $3 \mathrm{~m}$. Figure 7 shows the predicted and measured hydraulic conductivities. Small square boxes indicted a range of measured hydraulic conductivities. The hydraulic conductivity profile based on uncorrected pore pressures (for OC soils) is shown with a dashed line. It can be noted that, after applying the correction, the hydraulic conductivity profile has closely agreed with the measured data.

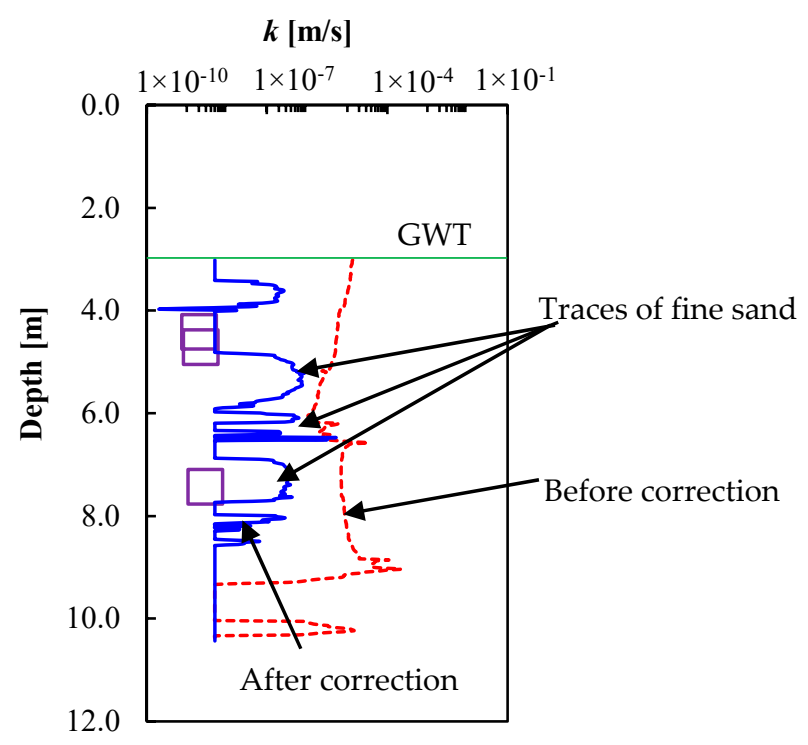

Figure 7. Measured and estimated hydraulic conductivity profile for Lincoln, NE, USA site.

\subsection{Cowden, UK}

This site is located on the east coast of Britain, about $23 \mathrm{~km}$ north-east of Kingston upon Hull [30]. The soil profile at this site is formed by glacial deposition. It is composed of principally overconsolidated clay dominated tills with lumps of chalk and harder stones with dimensions greater than $25 \mathrm{~mm}$. These layers are separated by thin layers of silt, sand, and fine gravel of varying extents. The tills are inorganics, well graded, dense and with low activity. The $O C R$ is reported to drop from 4 in the upper depth to 2 in lower depths. The GWT was taken as $2 \mathrm{~m}$. Figure 8 shows the hydraulic conductivity profiles for this site before and after applying correction. The average hydraulic conductivity reported for this site is $2.85 \times 10^{-10}$ to $4.44 \times 10^{-10} \mathrm{~m} / \mathrm{s}$ [4] as shown in Figure 8. The site showed a relatively uniform hydraulic conductivity profile with practically undrained response. Comparable with the measured data, the predicted profile also showed the cut-off limit $\left(\leq 5 \times 10^{-9} \mathrm{~m} / \mathrm{s}\right)$ for most part of the depth except for intermittent layers of sand and gravel.

\subsection{Cheongna, Incheon, South Korea}

This area is located in northwestern of South Korea, bordering Seoul and Gyeonggi to the east [31]. It mainly consists of silty clay soil which is separated by sandy soils from $6 \mathrm{~m}$ to $12.5 \mathrm{~m}$. The clay layer is classified as CL with liquid limit ranging from 30 to $50 \%$. OCR ranges from 0.62 to 5.50 . The GWT was reported to be $1 \mathrm{~m}$ below the ground surface. Figure 9 shows the hydraulic conductivity profiles for this site. Hydraulic conductivity determined by oedometer was reported to vary on average from $4.82 \times 10^{-10}$ 
to $8.96 \times 10^{-9} \mathrm{~m} / \mathrm{s}$. The corrected profile closely agreed with measured hydraulic conductivity. A higher hydraulic conductivity is detected for sandy layer from 6 to $12 \mathrm{~m}$ consistent with the reported type of soils.

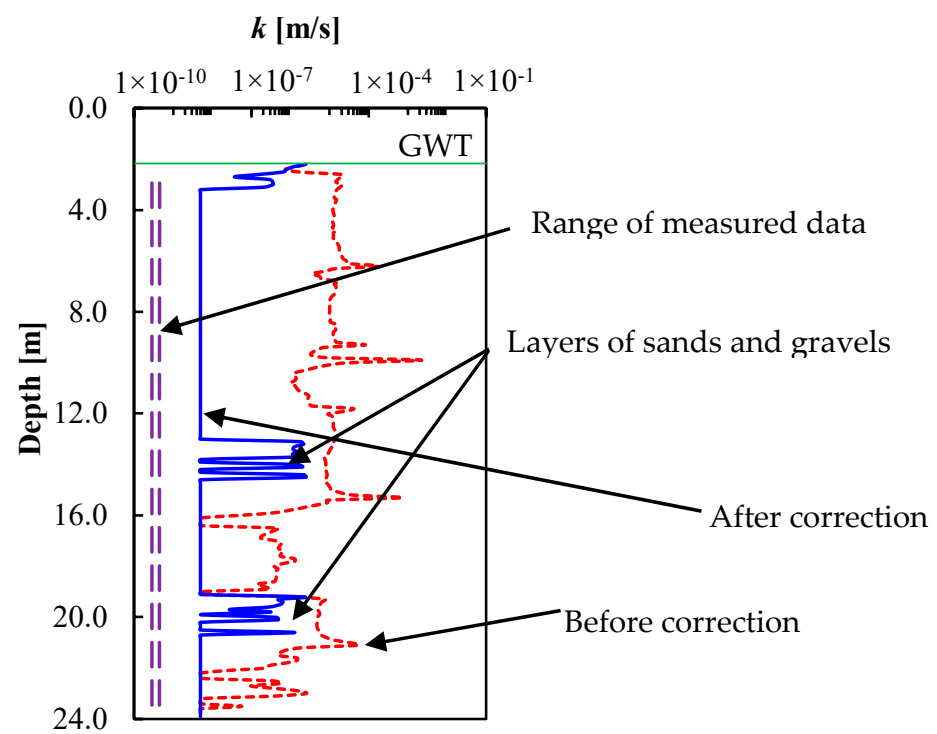

Figure 8. Measured and estimated hydraulic conductivity profile for Cowden, UK site.

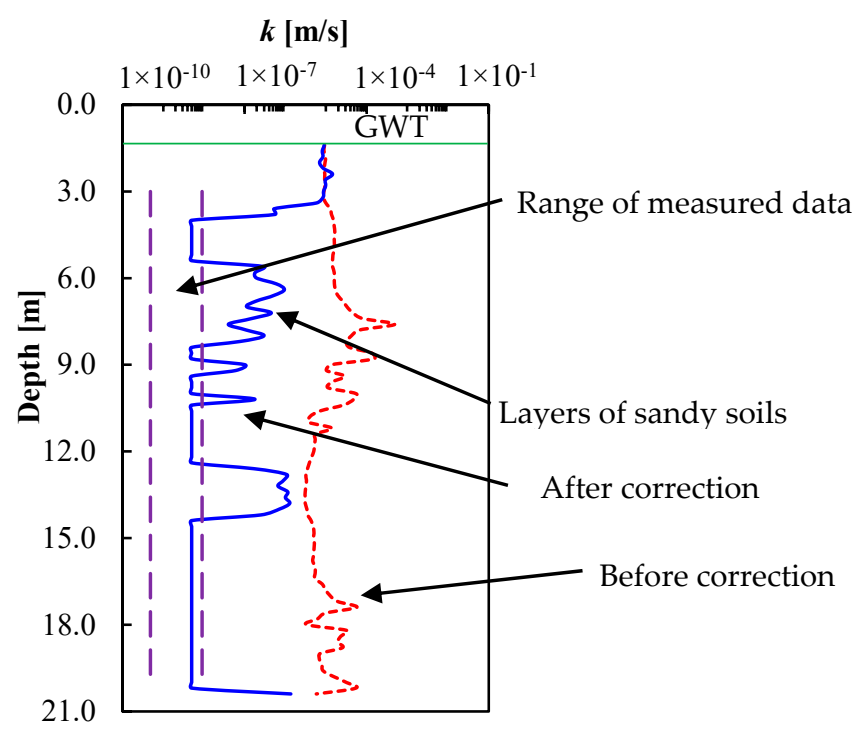

Figure 9. Measured and estimated hydraulic conductivity profile for Cheongna, Incheon site.

\subsection{SR18, Indiana, USA}

This area is situated near the west side of a bridge over bachelor's run, on state road 18 in Carroll county, Indiana [32]. It mainly consists of slightly OC to NC clay-like silt soil. The top clayey silt layer that exists up to a depth of $2.2 \mathrm{~m}$ is relatively stiffer than that exit below $5.2 \mathrm{~m}$. The GWT is reported to be about $4.5 \mathrm{~m}$ below the ground surface. Average coefficient of consolidations determined from the oedometer test were reported at $7.7,9.6$ and $9.8 \mathrm{~m}$ depths as $0.00467,0.0472$ and $0.0691 \mathrm{~cm}^{2} / \mathrm{s}$, respectively. Independently evaluated constrained compressibility from the net cone tip resistance measurements were used to predict the hydraulic conductivities of the soils. From these data, the hydraulic conductivities were computed as $1.50 \times 10^{-8}, 5.00 \times 10^{-8}$ and $1.55 \times 10^{-7} \mathrm{~m} / \mathrm{s}$ at a depth of 7.7, 9.6 and $9.8 \mathrm{~m}$, respectively. Figure 10 shows the measured and predicted hydraulic conductivity profile. Generally, there is good agreement between the two despites at $7.7 \mathrm{~m}$ there is a two-order difference. This may be attributed to the fact that hydraulic 
conductivities are estimated from oedometer test which provide predominantly vertical flow while PCPT provide a larger portion of horizontal flow.

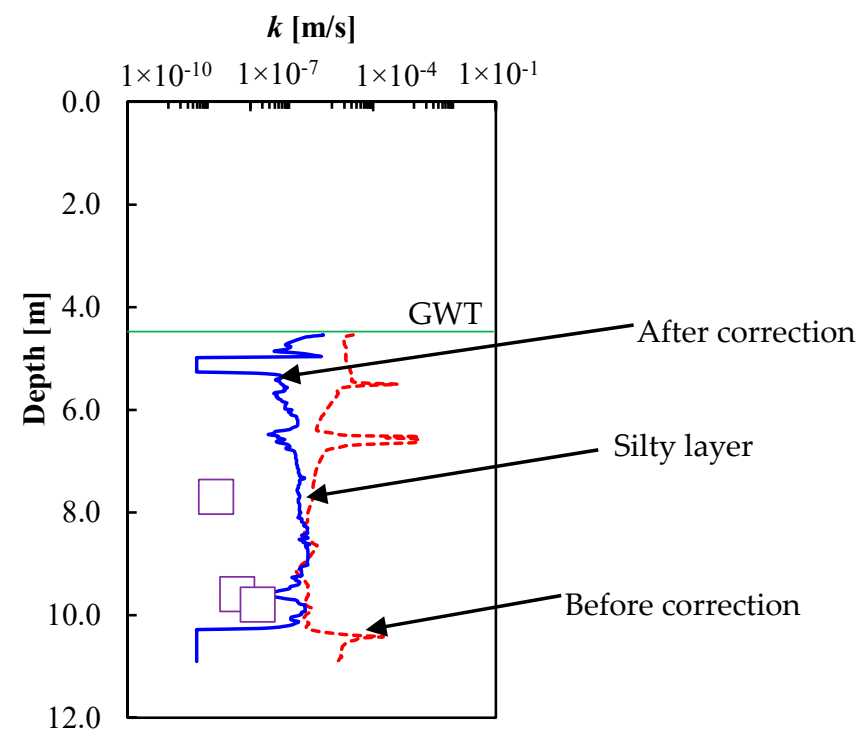

Figure 10. Measured and estimated hydraulic conductivity profile for SR18, Indiana, USA site.

\section{Summary and Conclusions}

A method has been proposed for the estimation of hydraulic conductivity of OC soils from PCPT results. A previously developed method for NC soils is revised to accommodate OC soils. The nonstandard pore pressure in OC soils is adjusted using a correction factor. The correction factor is formulated using the concepts of critical state soil mechanics, cavity expansion, and consolidation theory. The resulting analytical equation is reformulated using normalized cone indices so that hydraulic conductivity is estimated "on-the-fly".

It is shown that the correction factor is comprised of an undrained correction and an additional partial drainage parameter. Moreover, the correction factor is found to be mainly a function of cone tip resistance, friction ratio, pore pressure, and the rigidity index of OC soils. Two possible correction factors may be applied for the same input parameters. One is higher than half of the undrained correction and the other is lower than the undrained correction. In dilatory OC soils, since the pore pressure is low, higher correction is applied, whereas in sandy soils, lower correction is applied. The SBTn index, which entirely relies on PCPT parameters, is used to differentiate sands from other types of soils.

Use of the proposed method on actual test data showed the necessity of applying correction before predicting hydraulic conductivity. This was observed by the noticeable differences between profiles of hydraulic conductivities before and after correction. Comparison of post-correction estimated hydraulic conductivity with measured data from different sites indicated the promising applicability of the proposed method. The estimated hydraulic conductivity of OC soils based on PCPT data from USA, South Korea, and UK was satisfactory with measured hydraulic conductivity. Finally, this method may be a potentially viable option, particularly when one considers time, accuracy, and resolution of estimation (per $0.02 \mathrm{~m}$ depth) at the same time.

Author Contributions: Conceptualization, C.R.S., G.J., and M.L.; Methodology, C.R.S. and B.M.B.; Funding acquisition M.L.; Resources, M.L.; Writing—original draft preparation, B.M.B.; Writingreview and editing, B.M.B. and C.R.S. All authors have read and agreed the published version of the manuscript.

Funding: This research was funded by Nebraska Department of Transportation, grant number M063 and M076.

Institutional Review Board Statement: Not applicable. 
Informed Consent Statement: Not applicable.

Data Availability Statement: The data presented in this study are available on request from the corresponding author.

Acknowledgments: This study was possible due to the financial support by the Nebraska Department of Transportation through grants M063 and M076. The authors appreciate the financial and technical support from this funding agency.

Conflicts of Interest: The authors declare no conflict of interest.

\section{References}

1. Burns, S.E.; Mayne, P.W. Penetrometers for Soil Permeability and Chemical Detection; Geosystems Engineering Group, School of Civil \& Environmental Engineering: Atlanta, Georgia, 1998.

2. Voyiadjis, G.Z.; Song, C.R. Determination of Hydraulic Conductivity Using Piezocone Penetration Test. Int. J. Geomech. 2003, 3, 217-224. [CrossRef]

3. Senneset, K.; Sandven, R.; Janbu, N. Evaluation of Soil Parameters from Piezocone Tests. Transp. Res. Rec. 1989, $24-37$.

4. Robertson, P.K.; Sully, J.P.; Woeller, D.J.; Lunne, T.; Powell, J.J.M.; Gillespie, D.G. Estimating Coefficient of Consolidation from Piezocone Tests. Can. Geotech. J. 1992, 29, 539-550. [CrossRef]

5. $\quad$ Song, C.R.; Bekele, B.M.; Sawyer, B. Piezocone Penetration Testing Device; Nebraska Transportation Center: Lincoln, Nebraska, 2017.

6. Song, C.R.; Voyiadjis, G.Z.; Tumay, M.T. Determination of Permeability of Soils Using the Multiple Piezo-Element Penetrometer. Int. J. Numer. Anal. Methods Geomech. 1999, 23, 1609-1629. [CrossRef]

7. Elsworth, D.; Lee, D.S. Permeability Determination from On-the-Fly Piezocone Sounding. J. Geotech. Geoenviron. Eng. 2005, 131, 643-653. [CrossRef]

8. Song, C.R.; Pulijala, S. Hydraulic Property Estimation Using Piezocone Results. J. Geotech. Geoenviron. Eng. 2010, 136, 456-463. [CrossRef]

9. Chai, J.C.; Agung, P.M.A.; Hino, T.; Igaya, Y.; Carter, J.P. Estimating Hydraulic Conductivity from Piezocone Soundings. Géotechnique 2011, 61, 699-708. [CrossRef]

10. Abu-Farsakh, M.Y.; Voyiadjis, G.Z.; Tumay, M.T. Numerical Analysis of the Miniature Piezocone Penetration Tests (PCPT) in Cohesive Soils. Int. J. Numer. Anal. Methods Geomech. 1998, 22, 791-818. [CrossRef]

11. Sully, J.P.; Campanella, R.G. Evaluation of Field CPTU Dissipation Data in Overconsolidated Fine-Grained Soils. In Proceedings of the International Conference on Soil Mechanics and Foundation Engineering, New Delhi, India, 5-10 January 1994; pp. $201-204$.

12. Burns, S.E.; Mayne, P.W. Monotonic and Dilatory Pore-Pressure Decay during Piezocone Tests in Clay. Can. Geotech. J. 2011. [CrossRef]

13. Ren, X.W.; Santamarina, J.C. The Hydraulic Conductivity of Sediments: A Pore Size Perspective. Eng. Geol. 2018, 233, 48-54. [CrossRef]

14. Anderson, M.P. Heat as a Ground Water Tracer. Groundwater 2005, 43, 951-968. [CrossRef] [PubMed]

15. Wood, D.M. Soil Behaviour and Critical State Soil Mechanics; Cambridge University Press: Cambridge, UK, 1990.

16. Vesic, A.S. Expansion of Cavities in Infinite Soil Mass. J. Soil Mech. Found. Div. 1972, 98, 265-290. [CrossRef]

17. Mayne, P.W. Determination of OCR in Clays By Piezocone Tests Using Cavity Expansion and Critical State Concepts. Soils Found. 1991, 31, 65-76. [CrossRef]

18. Chen, B.S.; Mayne, P.W. Profiling the Overconsolidation Ratio of Clays by Piezocone Tests; School of Civil and Environmental Engineering, Georgia Institute of Technology: Atlanta, Georgia, 1994.

19. Schneider, J.A.; Randolph, M.F.; Mayne, P.W.; Ramsey, N.R. Analysis of Factors Influencing Soil Classification Using Normalized Piezocone Tip Resistance and Pore Pressure Parameters. J. Geotech. Geoenviron. Eng. 2008, 134, 1569-1586. [CrossRef]

20. Teh, C.I.; Houlsby, G.T. An Analytical Study of the Cone Penetration Test in Clay. Geotechnique 1991, 41, 17-34. [CrossRef]

21. Verruijt, A. Theory and Problems of Poroelasticity. Delft Univ. Technol. 2013, 71, 266.

22. Kulhawy, F.H.; Mayne, P.W. Manual on Estimating Soil Properties for Foundation Design; Electric Power Research Institute: Palo Alto, CA, USA, 1990.

23. Abu-Farsakh, M.; Tumay, M.; Voyiadjis, G. Numerical Parametric Study of Piezocone Penetration Test in Clays. Int. J. Geomech. 2003, 3, 170-181. [CrossRef]

24. Robertson, P.K. The James K. Mitchell Lecture: Interpretation of in-Situ Tests-Some Insights. In Proceedings of the 4th International Conference on Geotechnical and Geophysical Site Characterization-ISC'4, Porto de Galinhas, Brazil, 18-21 September 2012; Taylor \& Francis Group: London, UK, 2013; pp. 3-24.

25. Skempton, A.W. Long-Term Stability of Clay Slopes. Géotechnique 1964, 14, 77-102. [CrossRef]

26. Kim, T.; Kim, N.-K.; Tumay, M.T.; Lee, W. Spatial Distribution of Excess Pore-Water Pressure Due to Piezocone Penetration in Overconsolidated Clay. J. Geotech. Geoenviron. Eng. 2007, 133, 674-683. [CrossRef]

27. Mayne, P.W. Cone Penetration Testing; NCHRP Synthesis 368; Transportation Research Board: Washington, DC, USA, 2007; ISBN 978-0-309-09784-0. 
28. Robertson, P.K. Cone Penetration Test (CPT)-Based Soil Behaviour Type (SBT) Classification System-An Update. Can. Geotech. J. 2016, 53, 1910-1927. [CrossRef]

29. Robertson, P.K.; Cabal, K.L. Estimating Soil Unit Weight from CPT. In Proceedings of the 2nd International Symposium on Cone Penetration Testing, Huntington Beach, CA, USA, 9-11 May 2010; pp. 2-40.

30. Lunne, T.; Powell, J.J.; Robertson, P.K. Cone Penetration Testing in Geotechnical Practice; Routledge: New York, NY, USA, 1997.

31. Kaya Engineering Co. Technical Rewview of Ground Improvement Techniques for Developing Chungra Free Trading Area (District 1); Kaya Engineering: Incheon, Korea, 2005; p. 104.

32. Kim, K. Cone Penetration Test in Clayey Soil: Rate Effect and Application to Pile Shaft Resistance Calculations. Ph.D. Thesis, Purdue University, West Lafayette, IN, USA, 2005. 